\title{
Intrathecal Fibrinolytic Therapy after Subarachnoid Hemorrhage: Dosage Study in a Primate Model and Review of the Literature
}

\author{
J.M. Findlay, B.K.A. Weir, K. Kanamaru, M. Grace, P. Gordon, R. Baughman and A. Howarth
}

\begin{abstract}
Because of the naturally low fibrinolytic activity of CSF many erythrocytes entrapped in subarachnoid blood clot undergo hemolysis in situ, releasing vasogenic oxyhemoglobin $(\mathrm{OxyHb})$ in high concentrations around the basal cerebral arteries. In order to promote more rapid clearance of erythrocytes from the basal subarachnoid cisterns we are currently investigating intrathecal thrombolytic therapy with human, recombinant, tissue plasminogen activator (rt-PA) in a primate model of subarachnoid hemorrhage (SAH) and cerebral vasospasm (VSP). In the present study 16 monkeys were divided into 4 groups of 4 , and each group received a different dose of sustained-release gel rt-PA at the time of experimental SAH. Cerebral angiography seven days later showed that whereas no VSP occurred in the groups receiving 0.5 or $0.75 \mathrm{mg}$ of rt-PA, mild to moderate VSP occurred in the groups receiving 0.125 or $0.25 \mathrm{mg}$ of rt-PA. Analysis of the combined 2 smaller dosage groups revealed significant $(\mathrm{P}<0.05)$ reduction of lumen caliber in the clotside internal carotid (C3 and C4), proximal anterior cerebral (A1) and middle cerebral (MCA) arteries. Gross subarachnoid clot remained in all of the animals in the 0.125 and $0.25 \mathrm{mg}$ dose groups, in 2 of the animals in the $0.5 \mathrm{mg}$ dose group, and none of the animals in the $0.75 \mathrm{mg}$ dose group. It was concluded that $0.75 \mathrm{mg}$ of gel rt-PA is sufficient to completely lyse a $4.25 \mathrm{ml} \mathrm{SAH}$ and prevent VSP in our primate model. The literature on fibrinolysis and erythrocyte clearance in cerebrospinal fluid (CSF) is reviewed.
\end{abstract}

RÉSUMÉ: Thérapie fibrinolytique intrathécale après une hémorragie sous-arachnoïdienne: Étude posologique chez un primate et revue de la littérature Â cause du bas niveau naturel d'activité fibrinolytique du LCR, plusieurs erythrocytes isolés dans un caillot sanguin sous-arachnoïdien s'hémolysent in situ, libérant de l'oxyhémoglobine $(\mathrm{OxyHb})$ très concentrée autour des artères de la base du cerveau. Afin de favoriser l'élimination plus rapide des érythrocytes des citernes sous-arachnoïdiennes de la base, nous étudions présentement une thérapie thrombolytique intrathécale avec un activateur du plasminogène tissulaire humain, produit par technique de recombinaison (rt-PA), utilisant comme modèle un primate avec homorragie sous-arachnoïdienne (HSA) et vasospasme cérébral (VSP). Dans cette étude, 16 singes ont été répartis en 4 groupes de 4 sujets et chaque groupe a reçu une dose différente d'une préparation retard sous forme de gel de rt-PA au moment de l'HSA expérimentale. Une angiographie cérébrale pratiquée sept jours plus tard a montré qu'aucun VSP ne s'est produit dans les groupes recevant 0.5 ou $0.75 \mathrm{mg}$ de rt-PA, alors qu'un VSP léger à modéré s'est produit dans les groupes recevant 0.125 ou $0.25 \mathrm{mg}$ de rt-PA. L'analyse des données combinées des 2 groupes recevant les doses les plus faibles a montré une réduction significative $(P<0.05)$ du calibre de la lumière de la carotide interne ( $\mathrm{C} 3$ et $\mathrm{C} 4)$, de la cérébrale antérieure proximale ( $\mathrm{Al}$ ) et de la cérébrale moyenne (ACM) du côté du caillot. Un caillot sous-arachnoïdien macroscopique persistait chez tous les animaux des groupes recevant 0.125 et $0.25 \mathrm{mg}$, chez 2 des animaux du groupe recevant $0.5 \mathrm{mg}$ et chez aucun des animaux du groupe recevant $0.75 \mathrm{mg}$. Nous avons conclu que $0.75 \mathrm{mg}$ de gel rt-PA est une dose suffisente pour lyser complètement une HSA de $4.25 \mathrm{ml}$ et prévenir un VSP chez notre modèle animal, un primate. Nous revoyons la littérature sur la fibirnolyse et l'élimination des érythrocytes du LCR.

Can. J. Neurol. Sci. $1989 ; 16: 28-40$

A major complication of aneurysmal subarachnoid hemorrhage (SAH) is a form of cerebral arterial narrowing most commonly referred to as vasospasm (VSP). Peaking in incidence and severity approximately one week after aneurysm rupture, VSP and the resultant reduction in cerebral blood flow may lead to ischemia and infarction in the territories of the affected arter-

From the Division of Neurosurgery (JMF, BKA, KK, AH), Department of Surgery (MG), Division of Hematology (PG), and Department of Pharmacological Sciences (RB), Genentech Inc., San Francisco

Presented in part at the XXIII Canadian Congress of Neurological Sciences in Quebec, June 1988. Dr. Findlay was awarded the K.G. MacKenzie Memorial Award by the Canadian Neurosurgical Society for the best paper submitted by a neurosurgical resident.

Reprint requests to: J. Max Findlay, Division of Neurosurgery, 2D1.02 Mackenzie Health Sciences Centre, 8440 - 112 Street, Edmonton, Alberta, Canada T6G 2B7 
ies. The development of VSP depends upon the presence of thick blood clots in the subarachnoid cisterns lying in sustained contact with the external cerebral arterial wall. Lysis of erythrocytes within the clot liberates oxyhemoglobin (OxyHb), which is a principal mediator of the pathological process. The primate model of SAH and VSP developed at the University of Alberta closely mimics the human condition and has proved valuable in exploring the pathogenesis, ${ }^{1-5}$ and testing potential treatments, ${ }^{6-11}$ of VSP. One promising treatment currently under investigation is intrathecal thrombolytic therapy with human, recombinant, tissue plasminogen activator (rt-PA). ${ }^{12,13}$ The administration of this fibrinolytic enzyme into cerebrospinal fluid (CSF) has been effective in promoting rapid clearance of subarachnoid hematoma from the basal cisterns and thereby preventing the development of VSP. Here we report the results of a dosage study using a new, sustained-release formulation of rt-PA, and review the theoretical basis of intrathecal thrombolytic treatment after SAH.

\section{Materials AND METhodS}

Details of the procedures for microsurgical exposure of the basal subarachnoid cisterns, induction of subarachnoid hemorrhage, cerebral angiography and animal sacrifice used in our primate model have been published elsewhere, ${ }^{12}$ and will only be outlined here. The protocol was evaluated and approved by the University of Alberta's Animal Ethics Review Committee, and experiments were conducted with strict adherence to the standards of the Canadian Council on Animal Care.

Sixteen female cynomolgous monkeys (Macaca fascicularis), weighing between 3.5 and $4 \mathrm{~kg}$ were divided into 4 groups of 4 . The members of the first group received $0.125 \mathrm{mg}$, the second group $0.25 \mathrm{mg}$, the third group $0.50 \mathrm{mg}$, and the fourth group $0.75 \mathrm{mg}$ of intraoperative, intrathecal sustainedrelease gel rt-PA. The gel is a specially formulated hyaluronidase preparation containing $\mathrm{rt}-\mathrm{PA}, 1 \mathrm{mg} / \mathrm{ml}$, which goes into solution and releases rt-PA over a several day period (Genentech Inc., South San Francisco, CA, USA).

After baseline cerebral angiography the animals underwent a right fronto-temporal craniectomy for opening of the basal cisterns, exposure of the cerebral vessels and placement of 4.25 of autogenous blood clot into the subarachnoid space (Figure 1). Prior to dural closure gel rt-PA was injected into the subarachnoid space in the vicinity of the Sylvian fissure, the dosage as described above.

The animals were followed for the development of any complications or delayed neurologic deficits.

Seven days after SAH and rt-PA administration the animals underwent repeat cerebral angiography and were killed by exsanguination. The brains were removed and photographed, and any remaining subarachnoid clot weighed.

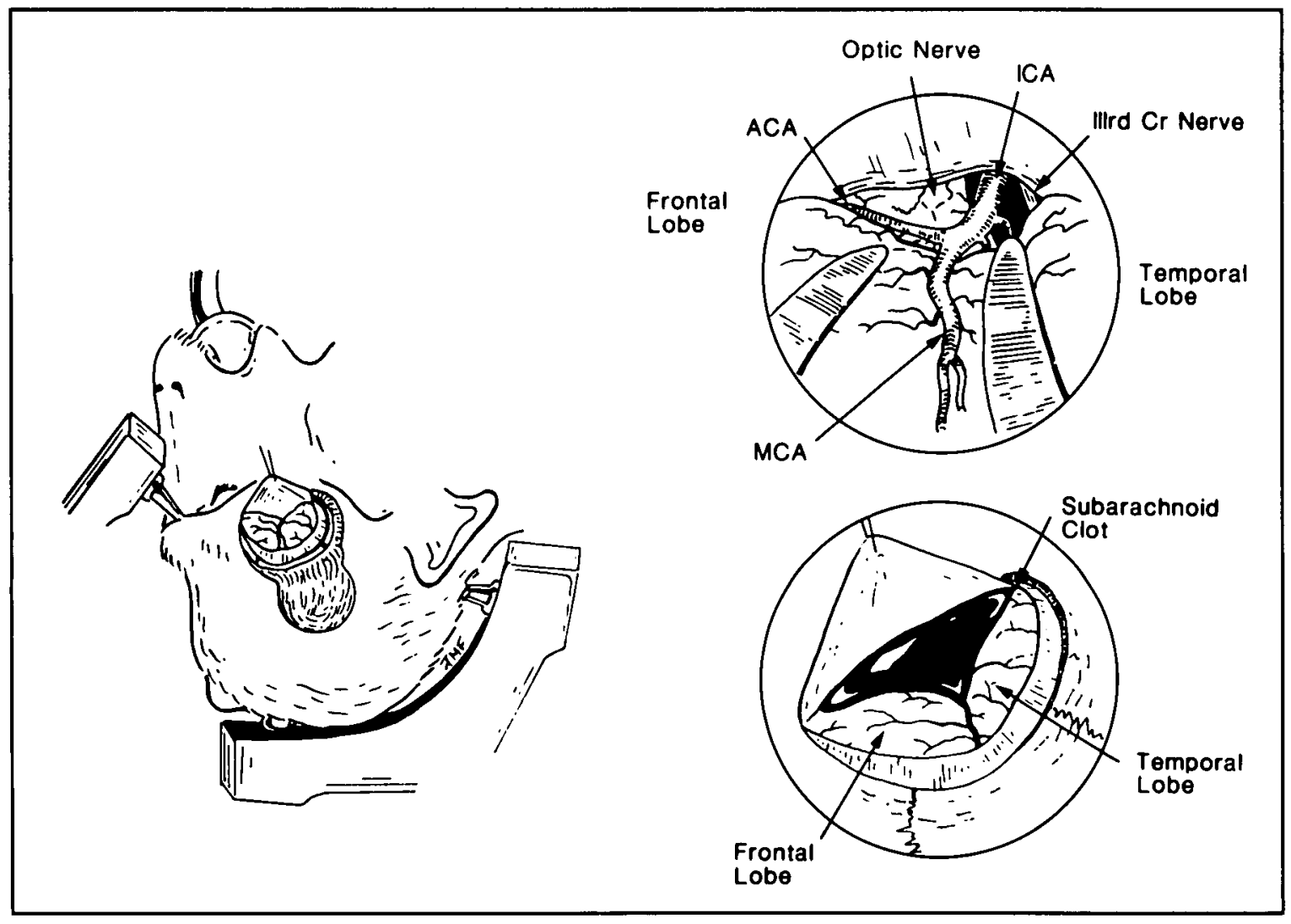

Figure 1 - Primate model of subarachnoid hemorrhage and chronic cerebral vasospasm. With the animals under anesthesia and controlled ventilation a right frontotemporal craniectomy is performed (left). After arachnoid is dissected free of the major anterior cerebral vessels (upper right) the subarachnoid space is filled with autogenous arterial blood clot (lower right). 
Cerebral vessels were measured 4 times with a calibrated optical micrometer, and a mean value obtained. The arteries were measured bilaterally at the following points: extradural internal carotid artery (C3), intradural internal carotid artery (C4), precommunicating segment of the ACA (A1), sphenoidal segment of the MCA, azygous distal anterior cerebral artery, the first part of the PCA, basilar artery and vertebral arteries.

All data were coded, entered into a computer, and edited. Data for angiographic vessel caliber change within treatment groups between days 0 and 7 were compared by a paired t-test, and intergroup comparisons were made with a $\mathrm{t}$-test for unpaired variables. Analysis of other measured indices was done with either a t-test or an analysis of variance where appropriate. The level of significance for all tests of comparison was $p<0.05$ unless otherwise stated.

\section{RESults}

Comparisons between the 4 dosage groups showed no significant differences in day 0 or day 7 values in body weight (mean weight, $3.31 \mathrm{~kg}$; SD, 0.32 for all 16 animals), heart rate (mean beats per minute, 110; SD, 15 for all 16 animals), or $\mathrm{PaCO}_{2}$, which was always adjusted to between 36 and $42 \mathrm{mmHg}$ at the time of cerebral angiography. The clinical condition of all animals remained good throughout the study period and there were no delayed neurologic deteriorations.

Mild to moderate VSP (between 10 and $50 \%$ reduction in vessel caliber compared to baseline) was seen in the C3, C4, A1 and MCA vessels in the 0.125 and $0.25 \mathrm{mg}$ dose groups, and this reduction was statistically significant in the case of $\mathrm{C} 4$ and the MCA in the $0.25 \mathrm{mg}$ group $(\mathrm{p}<0.05)$ (Table 1). The small number of animals in each group (4) appeared to preclude significance in the $0.125 \mathrm{mg}$ group. When the 8 animals in the 2 smaller dosage groups were combined, significant narrowing $(\mathrm{P}<0.05)$ was evident in all of the clot-side anterior cerebral arteries: C3, C4, Al and the MCA. No VSP was observed in the 0.5 and $0.75 \mathrm{mg}$ groups, alone or in combination (Figure 2).
Gross clot remained in the subarachnoid space of all 8 animals in the 0.125 and $0.25 \mathrm{mg}$ dose groups and in 2 of the 4 in the $0.5 \mathrm{mg}$ group. The animals in the $0.75 \mathrm{mg}$ group were all free of clot (Figure 3). These differences were statistically significant.

\section{Discussion}

\section{Cerebral Vasospasm}

In cases of aneurysmal SAH complicated by VSP the arterial narrowing is usually maximal 5 to 10 days after rupture. 14,15 The incidence and severity of VSP increases with greater volumes of blood clot present in the basal cisterns after SAH as demonstrated by computerized tomography, ${ }^{16,17}$ but the overall incidence among survivors of aneurysm rupture has been estimated to be about $50 \% .18$ Vasospasm can affect arteries and arterioles of all caliber, but it is most striking in the larger arteries which course through the subarachnoid cisterns on the ventral surface of the brain. These are the same arteries upon which saccular aneurysms arise and consequently those which have greatest exposure to thick blood clot after aneurysm bleeding. The relative rarity of VSP complicating other etiologies of SAH (e.g. trauma or arteriovenous malformation rupture) is probably due to the infrequency of large cisternal blood clots in these conditions. There have been rare reports of symptomatic cerebral arterial narrowing following clipping of unruptured aneurysms, ${ }^{19}$ or presenting months after successful clipping of ruptured aneurysms, ${ }^{20}$ but such unusual cases suggest an arteriopathy fundamentally different than VSP as defined here.

From the foregoing it is evident that the pathogenesis of VSP lies in the subarachnoid clot and in its effect on the cerebral arterial wall. Subarachnoid clot breakdown, which consists of lysis of both its cellular and fibrin components, releases a number of chemical substances which have been considered potential "spasmogens". ${ }^{21}$ The concentration of these substances is maximal near the adventitial surface of the arteries travelling through the subarachnoid cisterns, and their access to the vari-

Table 1: Change in Clot (right)-Side Vessel Caliber and Remaining Clot in the 4 Dosage Groups

\begin{tabular}{lcccc}
\hline \hline & \multicolumn{4}{c}{ Dosage Group* } \\
$\begin{array}{l}\text { Vessel } \\
\text { Change } \dagger\end{array}$ & $\mathbf{0 . 1 2 5} \mathbf{~ m g}$ & $\mathbf{0 . 2 5} \mathbf{~ m g}$ & $\mathbf{0 . 5} \mathbf{~ m g}$ & $\mathbf{0 . 7 5} \mathbf{~ m g}$ \\
\hline C3 & $-14 \% \pm 16 \%$ & $-11 \% \pm 9 \%$ & $-1 \% \pm 14 \%$ & $+1 \% \pm 4 \%$ \\
C4 & $-20 \% \pm 20 \%$ & $-22 \% \pm 13 \%$ & $+1 \% \pm 18 \%$ & $-1 \% \pm 7 \%$ \\
& & $(\mathrm{P}=0.043)$ & & \\
Al & $-30 \% \pm 34 \%$ & $-38 \% \pm 19 \%$ & $-7 \% \pm 18 \%$ & $+15 \% \pm 15 \%$ \\
MCA & $-22 \% \pm 21 \%$ & $-25 \% \pm 13 \%$ & $-6 \% \pm 15 \%$ & $+4 \% \pm 9 \%$ \\
& & $(\mathbf{P}=0.035)$ & & \\
Weight of & & & & \\
$\begin{array}{l}\text { Remaining } \\
\text { Clot }\end{array}$ & 0.2250 & 0.1375 & 0.0675 & \\
(gm \pm standard & \pm 0.031 & \pm 0.118 & \pm 0.122 & \\
deviation) & & & & \\
\hline
\end{tabular}

*4 animals in each group.

†Values are percentage change in vessel caliber $(\mathrm{mm})$, day 7 compared to day $0, \pm$ standard deviations, for the right (clot)-sided cerebral arteries. Where the change is statistically significant, the $P$ value is given.

C3 = extradural internal carotid artery; $\mathrm{C} 4=$ intradural internal carotid artery; $\mathrm{Al}=$ precommunicating segment of anterior cerebral artery; $\mathrm{MCA}=$ sphenoidal segment of middle cerebral artery. 


\section{Do}

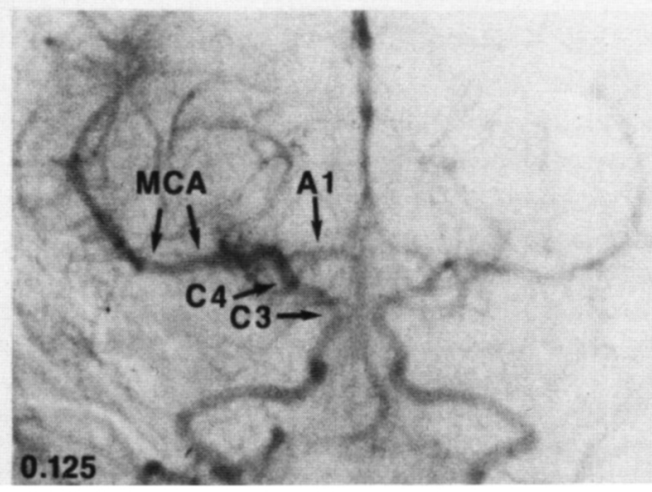

\section{D7}
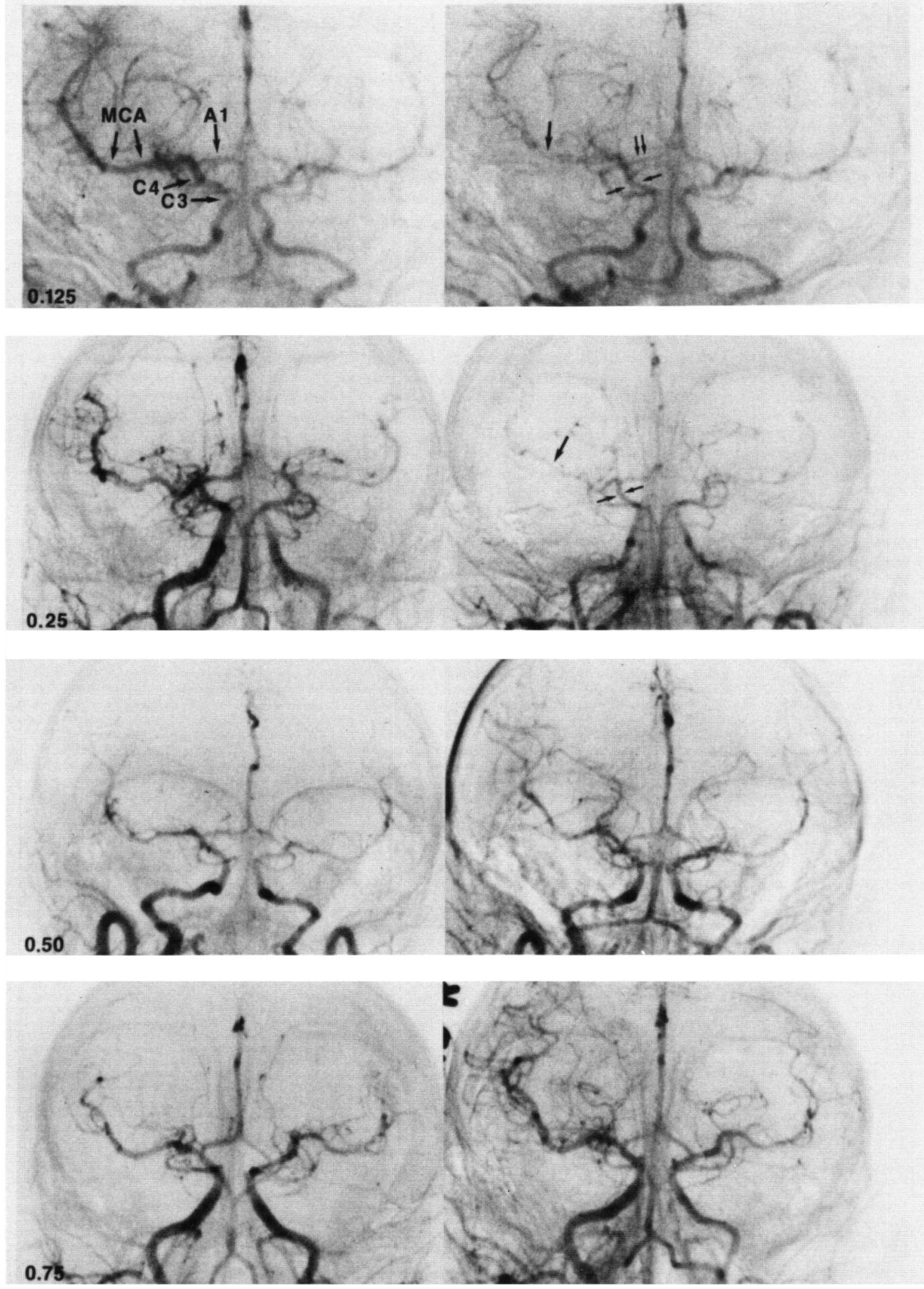

Figure 2 - Examples of day 0 (left) and day 7 (right) anteroposterior cerebral angiograms from a monkey in each dosage goup. The right (clot-side) middle cerebral (MCA), proximal anterior cerebral (A), intradural internal carotid (C3) and extradural internal carotid (C4) arteries are labeled in the day 0 angiogram of the $0.125 \mathrm{mg}$ dosage group example. Note the presence of vasospasm in these vessels after 7 days in the $0.125 \mathrm{mg}$ and $0.25 \mathrm{mg}$ examples (arrows), in contrast to the normal appearing day 7 angiograms in the 0.50 and $0.75 \mathrm{mg}$ group examples. 


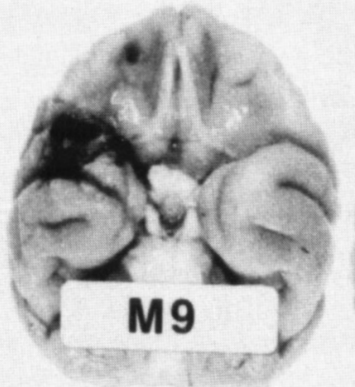

$0.125 \mathrm{mg}$

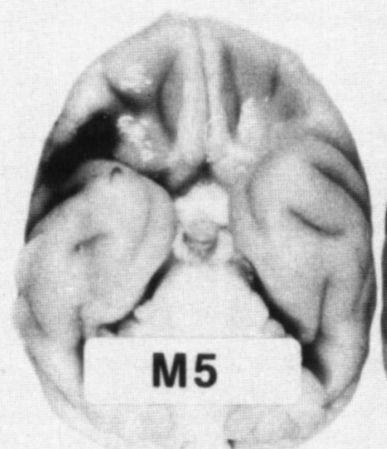

$0.25 \mathrm{mg}$

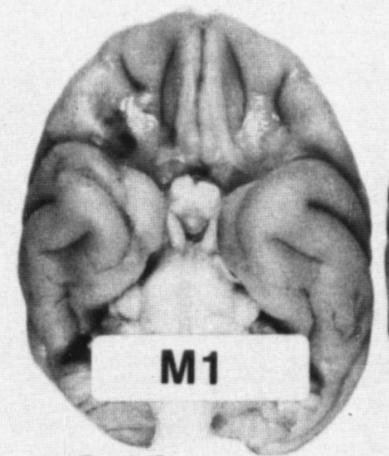

$0.50 \mathrm{mg}$

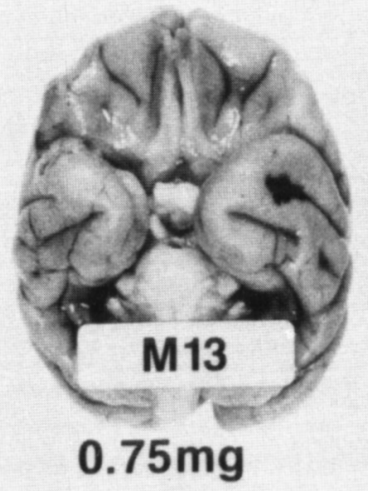

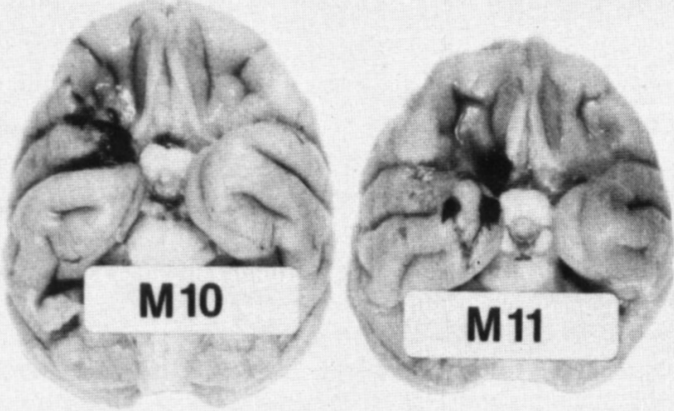
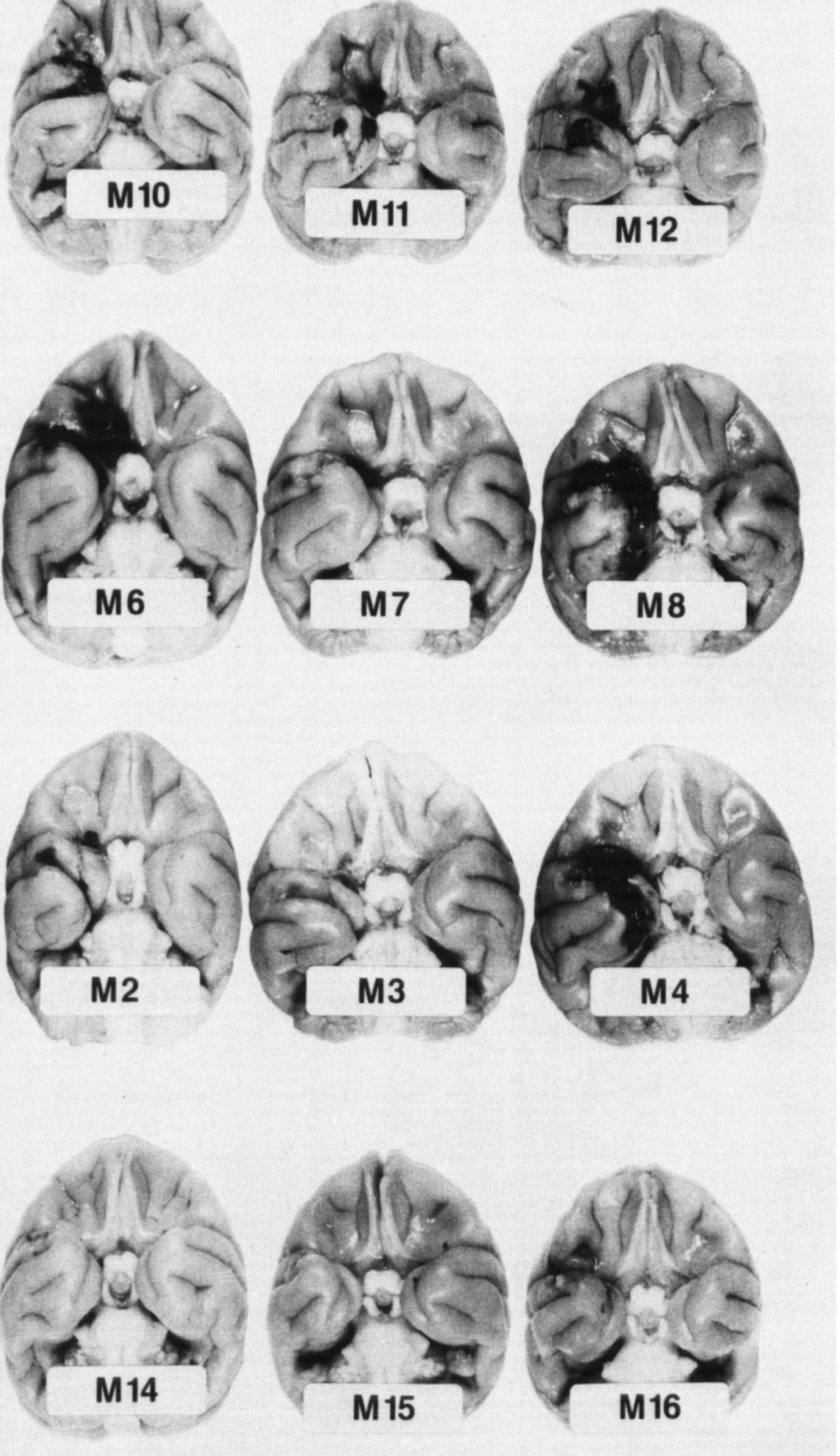

Figure 3 - All eight monkeys in the 0.125 and $0.25 \mathrm{mg}$ dosage groups had gross subarachnoid blood clot remaining on the ventral surface of the brain at necropsy (MS to MI2), and some clot was present in 2 animals in the $0.50 \mathrm{mg}$ group (M2 and M4). All 4 monkeys in the $0.75 \mathrm{mg}$ group were free of clot (M13 to MI6). 

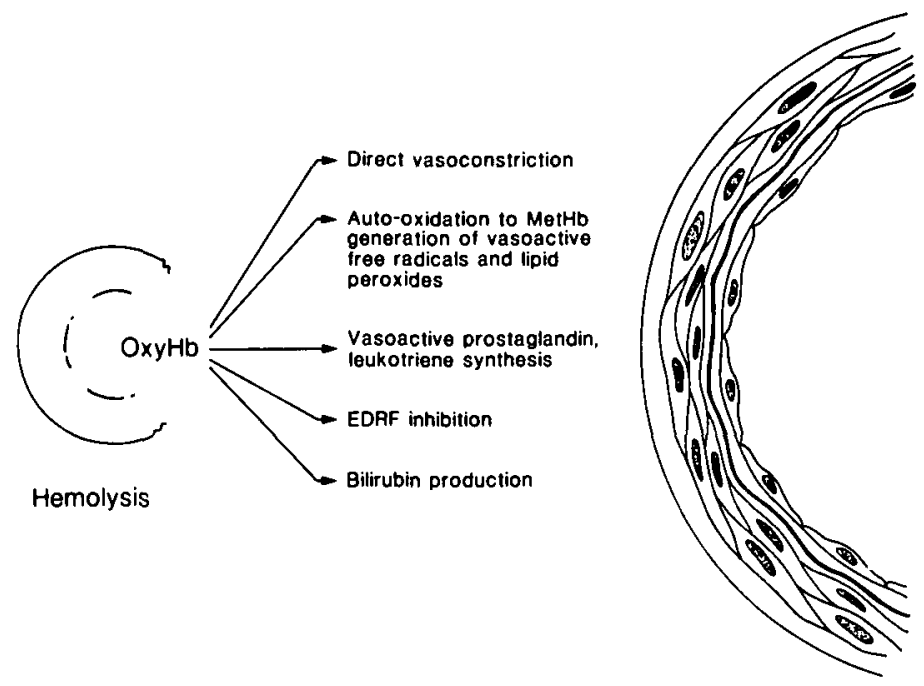

Figure 4-Hemolyzing erythrocytes entrapped in periarterial subarachnoid clot expose the external cerebral arterial wall to a high concentration of oxyhemoglobin $(\mathrm{OxyHb})$, which is the principal mediator of vasospasm. A number of mechanisms have been proposed to explain the effect of $O x y H b$ on the vessel wall, including: 1 . a direct vasoconstrictive activity, 2. the generation of vasoactive and vasotoxic free radical species following autooxidation of $\mathrm{OxyHb}$ to methemoglobin $(\mathrm{MetHb}), 3$. the generation of vasoactive prostaglandins or leukotrienes, and 4 . the production of bilirubin, which may also be vasogenic (see text for references). ous layers of the vessel wall may be facilitated by adventitial stomas and pathways that communicate with the subarachnoid space. ${ }^{1,22}$ Of the many putative spasmogens liberated by the decaying subarachnoid clot, there is now considerable evidence that hemoglobin $(\mathrm{Hb})$ is the most important in the induction of VSP. The oxygenated form of the $\mathrm{Hb}$ molecule, oxyhemoglobin $(\mathrm{OxyHb})$, is released gradually over a number of days from the red blood corpuscles enmeshed in the periarterial subarachnoid clot, and its appearance in the CSF after SAH correlates roughly with the time course of VSP. ${ }^{23}$ As reviewed by Weir, ${ }^{24}$ numerous studies have demonstrated that red blood cell hemolysates induce prompt and sustained cerebral arterial vasoconstriction in vitro and when applied topically to exposed cerebral arteries in vivo. Intact red blood cells are not vasoactive, ${ }^{25}$ and methemoglobin (MetHb), the spontaneous auto-oxidation derivative of OxyHb that appears late and in relatively small concentrations in the CSF after SAH, is considerably less vasoactive than OxyHb. ${ }^{26,27}$ More recently, it has been shown that erythrocytes are the sole ingredient of whole blood responsible for chronic VSP in a cat ${ }^{28}$ and porcine ${ }^{29}$ model of SAH. Although Boullin et $\mathrm{al}^{30}$ failed to induce prolonged VSP in baboons with a single cisternal injection of pure $\mathrm{OxyHb}$, the dosage of pigment used was small and probably substantially diluted by CSF. Given the correlation between VSP and the presence of a large SAH, it is likely that a high periarterial concentration of OxyHb over several days is necessary to induce VSP (as would be provided by a thick, hemolyzing cisternal blood clot). Ohta et $a^{31}$ analyzed $\mathrm{Hb}$ concentrations in CSF and periarterial subarachnoid hematoma in patients with aneurysmal SAH. They considered even the maximum concentration of $\mathrm{Hb}$ seen in bloody CSF, approximately $5 \mathrm{~g} / \mathrm{dl}$, too low to produce VSP, wheras the concentration of $\mathrm{Hb}$ in periarterial clot, found as high as $30 \mathrm{~g} / \mathrm{dl}$, did appear to correlate with the incidence of VSP.

It is not yet clear exactly how OxyHb induces VSP in the cerebral arterial wall, although a number of mechanisms have been proposed (Figure 4). Although $\mathrm{OxyHb}$ itself induces a direct smooth muscle contractile response, ${ }^{32}$ its release into the extracellular milieu of the subarachnoid clot might also lead to the generation of various vasoactive free radicals, ${ }^{33}$ prostaglandins, ${ }^{34,35}$ and leukotrienes. ${ }^{36}$ Hemoglobin, as well as bloody CSF obtained from patients with SAH, inhibits endothelial-dependent relaxation in canine cerebral arteries, ${ }^{37}$ suggesting another mechanism in the development of VSP.

Finally, it has recently been shown that another breakdown product of $\mathrm{Hb}$ found in subarachnoid clots and CSF after SAH, bilirubin, can result in pathological changes similar to VSP when applied topically to cat and baboon basilar arteries over a period of 4 hours. ${ }^{38}$

Management strategies for VSP can be grouped under the following headings: (1) pharmacologic prevention or reversal of the arterial narrowing, (2) hemodynamic augmentation of blood flow through the narrowed and collateral cerebral circulation, (3) cerebral cytoprotection from ischemia, (4) mechanical dilatation of the narrowed arteries by transluminal angioplasty, and (6) prevention of vasospasm through the removal of subarachnoid clot from the subarachnoid space. It is likely that many of these approaches will have a place to play in the overall management of this condition, but thus far the only proven method to prevent VSP has been subarachnoid clot removal. Clinical studies have suggested, ${ }^{39}$ and experimental studies in primates have shown, 8.9 that thorough surgical clot evacuation up until about 48 hours after SAH will reduce or prevent VSP, but beyond this time the clot-vessel wall interaction has progressed to a point where some degree of VSP is inevitable. Although surgery within this time-frame for definitive aneurysm clipping to prevent rebleeding is becoming increasingly popular, vigorous clot removal is difficult and dangerous after significant subarachnoid bleeding, and it is not attempted by most neurosurgeons today. We grew interested in developing a nonmechanical way of promoting clearance of intact erythrocytes from basal subarachnoid cisterns in order to prevent VSP. The rationale of fibrinolytic therapy for $\mathrm{SAH}$ is best considered after reviewing the natural history of subarachnoid bleeding into the subarachnoid space.

\section{Coagulation in the CSF}

The blood-brain barrier (BBB) largely excludes clotting factors from the cerebrospinal fluid (CSF), resulting in mean CSF 
values for these proteins ranging from $1-5 \%$ to that of blood. ${ }^{40}$ Barabas ${ }^{41}$ observed that diluting whole blood with CSF up until approximately a $1: 10$ ratio of blood to CSF resulted in more rapid clotting than whole blood alone, and he attributed this to the presence of a "clotting accelerating factor" in CSF. The thromboelastographic analyses of CSF-plasma mixtures by Hindersin et al ${ }^{42}$ verify this coagulation-promoting effect of both normal and pathological CSF, and these authors felt it was due to the presence of tissue thromboplastins in CSF. A sufficient volume of whole blood entering the subarachnoid space readily clots, the intrinsic pathway of the coagulation cascade being triggered by contact activation with collagen in the arachnoid trabeculae, ${ }^{43}$ and the extrinsic pathway activated by thromboplastic factors released from vessel wall, leptomeninges and parenchyma. The strong activation of the coagulation system in the subarachnoid space immediately after SAH was demonstrated by Kasuya et al, 43 who followed the CSF level of fobrinopeptide A (a peptide released in the formation of fibrin) by radioimmunoassay. The clotting process utilizes platelets, plasma clotting factors and fibrinogen entering the CSF as components of the hemorrhage. The volume of hemorrhage from a ruptured aneurysm varies greatly, ranging from a small leak which fails to clot to a massive bleed which not only congests the subarachnoid spaces but also spreads into brain and ventricles. The total volume of CSF in adults is approximately 150 $\mathrm{ml}$, and the volume of the basal subarachnoid cisterns is roughly one-third of this. The frequent finding of free erythrocytes in CSF after SAH which fail to clot or which form a "halo" on blotting paper (as opposed to red blood cells in plasma, which readily clot) is not due to a CSF inhibitory effect, but is simply due to the dilution of coagulation proteins beyond a blood-CSF ratio which can support the coagulation cascade at sites distant from the hemorrhage.

\section{Fibrinolysis in the CSF}

The fibrinolytic system is responsible for dissolution of fibrin clots and thrombi, and is comprised of a number of serine protease enzymes. These proteases have a similar basic structure, and in particular demonstrate extensive homologies in the vicinity of the three amino acid residues directly involved in peptide bond hydrolysis (the catalytic site) ${ }^{44}$ The active enzymes consist of two disulfide-linked chains. ${ }^{45}$ The longer chains possess disulfide triple-loop bridging patterns, the socalled "kringle structures", that contain lysine-binding sites for fibrin. The smaller chain contains the catalytic site, the specificity of which is imparted by nearby amino acid sequences and secondary structures. Central to the fibrinolytic system is the proenzyme plasminogen. ${ }^{46}$ Synthesized in the liver, it circulates in plasma in relatively high concentrations of 10 to $20 \mathrm{mg}$ per $100 \mathrm{ml}{ }^{47}$ It possesses five kringle structures which impart high affinity for fibrin, and it is adsorbed onto fibrin polymers as they form, moving from the unbound "soluble-phase" to the fibrin-bound "gel-phase". 48 Plasminogen is converted to the active enzyme plasmin by the selective splitting of a single argininevaline peptide bond, resulting in the two-chain structure of the active enzyme. The smaller chain's catalytic site is then free to hydrolyse susceptible fibrin arginine-lysine peptide bonds. Plasmin has a fairly broad range of specificity, hydrolyzing in addition to fibrin its proenzyme plasminogen, fibrinogen, coagulation factors V, VII and VIII, serum complement components and certain other plasma proteins. ${ }^{49}$ The physiologic significance of some of these reactions is uncertain, but several mechanisms are in place to compensate for this lack of specificity: 1 . plasmin is cleaved from plasminogen primarily in its gel-phase, making it inaccessible to other susceptible proteins, and 2. any plasmin that is free in plasma is rapidly inactivated by circulating plasmin inactivators, most importantly $\alpha 2$-antiplasmin and $\alpha$ 2-macroglobulin..$^{50}$ Plasmin activated on the fibrin surface is protected from reaction with these and other circulating inhibitors.

Since plasminogen becomes a normal clot component the regulation of fibrinolysis is exerted primarily through the availability of plasminogen activators. Locally generated and released endogenous activators include high fibrin affinity tissue plasminogen activator ( $\mathrm{t}-\mathrm{PA})$ and low fibrin affinity singlechain urokinase plasminogen activator (scu-PA). ${ }^{44}$ Each type of activator exists in several forms, but the active enzymes all appear to once again consist of a longer polypeptide chain possessing kringle structures and a shorter chain containing the catalytic site. The most important endogenous plasminogen activator is t-PA, which is synthesized by endothelial cells of arteries, veins and capillaries. ${ }^{51}$ Its release is triggered by a wide variety of stimuli, such as injury, ischemia, occlusion and the application of certain platelet-derived vasoactive agents. ${ }^{52}$ Tissue plasminogen activator circulates in only nanomolar levels in the blood where it complexes with a fast acting inhibitor and is cleared primarily by the liver. Its active circulating half-life is less than 10 minutes. ${ }^{49}$ Released on demand at the site of vessel injury and thrombus formation, t-PA's activity is protected by protein $\mathrm{Ca}$, which neutralizes the plasma inhibitor of $t-P A .53$ The kringle stuctures again serve to impart a strong affinity for fibrin, so that released t-PA diffuses into the thrombus, binds to fibrin polymers and proceeds to hydrolyse and activate the nearby fibrin-bound plasminogen into plasmin, which in turn cleaves fibrin and dissolves the clot. Minor plasminogen activator pathways employ factor XII, prekallikrein, and high-molecular weight kinogen, and descriptions of these as well as the precise molecular mechanisms of activation have recently been presented. $44,47,54$

Considerably more study has been devoted to the subject of fibrinolysis than to coagulation in the CSF, owing primarily to the interest in preventing aneurysm rebleeding after SAH with antifibrinolytic agents. Early studies, such as those by Porter et $a^{55,56}$ and Takashima et $a^{57}$ relied upon biological assays for measuring fibrinolytic activity (FA) of the CSF. In such assays the presence of plasminogen activator is detected through its conversion of plasminogen to plasmin on unheated fibrin plates, resulting in zones of lysis. ${ }^{58}$ Lysis on a heated fibrin plate indicates the presence of a free plasmin in the test sample, since heating destroys the plasminogen native to the fibrin plate. In the following studies fibrinolytic activity refers to plasminogen activator activity. These studies have shown that normal CSF lacks FA, although Takashima et al found that some FA could be detected after pneumoencephalography. Using Todd's histochemical method ${ }^{59}$ these authors also found that the endothelial cells of the brain and meninges appeared to be the source of FA. Porter's conclusion that the CSF contained a plasminogen "proactivator", the activity of which would be completed by the addition of streptokinase or the euglobulin component of plasma, are unfounded in light of their own or subsequent data. 
More recent studies employing immunoassays for fibrinolytic enzymes have confirmed the impressions of these earlier studies. Kun-yu Wu et al 60 found that normal CSF contains no or only trace amounts of plasminogen, but that plasminogen could be found in the CSF of patients with breakdown of the BBB related to various disease conditions, correlating with a general increase in CSF protein levels. Similarly, Hindersin and Endler $^{42}$ found physiologic CSF contains no plasminogen or $\mathrm{t}$ PA using immunoassay.

Whereas normal CSF does not contain fibrinolytic enzymes, the CSF obtained from patients with SAH has in some instances been shown to contain FA. In an early study Tovi et al61 examined FA by the fibrin plate method and fibrin degradation product (FDP) content of CSF samples taken at various times from aneurysmal SAH in 11 patients. Fibrinolytic activity was present in 7 of these patients at some point in time, and FDPs were seen in the CSF of all the patients within 3 days of the hemorrhage. Hassler and Fodstad, using Todd's technique, found that tiny vessels in the adventitia of both ruptured and unruptured aneurysms produce plasminogen activator, pointing to one possible source of FA after SAH.62 The development of simple radioimmunoassays for FDPs led to a number of reports demonstrating rapid and large increases in the concentrations of these fragments in CSF after SAH, 63 although not all investigators felt that their presence reflected fibrinolysis in the CSF alone. Anderson et al ${ }^{64}$ felt the coexistence in CSF of FDP fragments $\mathrm{D}$ and $\mathrm{E}$ with other low molecular weight proteins (plasminogen and factor IX), but not with larger proteins (fibrinogen and factor V), was more consistent with FDP leakage from the meninges or plasma into the CSF across a damaged BBB due to aseptic meningitis. Steinmetz and Grote concurred with this, ${ }^{65}$ and were unable to demonstrate any CSF plasmin or t-PA using sensitive enzyme kinetic and immunological methods in 14 patients after SAH. Vermeulen et al ${ }^{66}$ measured CSF FDPS between days 9 and 15 after SAH in 22 patients receiving an antifibrinolytic agent and 26 patients given placebo. Although rebleeding was significantly reduced in the former group, no difference was found in FDP levels between groups nor was any relationship evident between FDP levels and rebleeding. These authors also concluded that FDPs in the CSF reflect a damaged blood-CSF barrier rather than fibrinolysis in the subarachnoid space alone.

After experimental SAH in rabbits Fodstad et al demonstrated that the ineninges were a source of plasminogen activator, although no controls were included in this study to allow comparison of meningeal FA in normal versus SAH animals. ${ }^{67}$ Fodstad and Nilsson did study 41 patients with recently ruptured aneurysms and found that CSF plasminogen activator activity measured by fibrin plate assay increased after 1 week in the 20 not treated with the antifibrinolytic agent tranexamic acid. 68

In summary, it appears that modest fibrinolytic activity is sometimes seen in the CSF after aneurysmal SAH as well as in other conditions that irritate the meninges. ${ }^{69}$ This is due to the release of $\mathrm{t}-\mathrm{PA}$ from endothelium of small vessels in the meninges and perhaps the adventitia of major cerebral vessels and the aneurysm sac itself. Plasma protein leakage across a damaged BBB as well as leukocytes and platelets contained within the subarachnoid thrombus are additional sources of plasminogen activators. ${ }^{42}$ These plasminogen activators diffuse into subarachnoid clot, bind to fibrin, and activate plasminogen that was carried into the subarachnoid space as part of the hemorrhage and which became incorporated into the developing coagulum. Because of the affinity of t-PA for fibrin, t-PA activity measured in the CSF may not always detect the presence of local fibrinolysis in subarachnoid clot. Fibrin degradation products released into the CSF are derived from both subarachnoid clot lysis and a meningitic reaction. The elevation of FDPs correlates with the size and severity of $\mathrm{SAH}$, and hence also with the risk of VSP. ${ }^{70}$ Despite the near absence of plasmin inhibitors in normal or blood-stained $\mathrm{CSF}^{42}$ the relatively meager supply of t-PA released allows fibrinolysis to proceed slowly in the subarachnoid space, as evidenced by the longevity of blood clots deposited in the cisterns. The clearance of subarachnoid clot is not dependent upon fibrinolysis, however, and it is frequently accompanied by a degree of fibrous tissue reaction. ${ }^{71}$ As shall be discussed, the cellular elements of the clot may be eliminated in situ by hemolysis or phagocytosis. In the future, application of extremely sensitive enzyme-linked immunoabsorbent assays for t-PA in large numbers of patients will more precisely define the CSF fibrinolytic response to SAH.

\section{Clearance of Erythrocytes from the CSF}

Since CSF is slightly hypertonic compared to plasma, erythrocytes extravasated into the subarachnoid space immediately become crenated. ${ }^{72}$ Deprived of plasma glucose, their sole energy source, as well as membrane-stabilizing plasma lipids and proteins, red blood cells are unable to maintain integrity of their cell membrane and begin hemolysing in CSF. Xanthochromia describes the color of CSF imparted by liberated heme pigments, and its presence within hours of SAH was recognized by Froin at the turn of the century as a valuable means of differentiating a "bloody tap" from a spontaneous subarachnoid hemorrhage. ${ }^{73}$ It appears that erythrocytes which escape to circulate freely in the CSF have a shorter life-span than those which become enmeshed in subarachnoid clots or clumped and trapped in the leptomeninges. ${ }^{72,74}$ Examining necropsy material from 53 patients who had died at various intervals after aneurysmal SAH, Hammes ${ }^{74}$ noted that blood in the subarachnoid space elicited a prompt outpouring of polymorphonuclear leukocytes, followed by the appearance of lymphocytes and large mononuclear phagocytes derived from the arachnoid. Red blood cell phagocytosis in the basal meninges was at its peak towards the end of the first week after SAH. In a similar study of 20 cases of SAH Alpers and Forster ${ }^{71}$ found that even up to 35 days from the hemorrhage clumps of red cells remained within organizing subarachnoid connective tissue in the basal subarachnoid cisterns.

Using absorption spectrophotometry as well as biochemical analysis of the CSF, Barrows and colleagues ${ }^{75}$ measured $\mathrm{OxyHb}, \mathrm{MetHb}$ and bilirubin in 31 patients after subarachnoid or ventricular hemorrhage. Oxyhemoglobin accounted for the orange xanthochromia seen within two hours of hemorrhage, and its level plateaued on the third or fourth day. At that time bilirubin could also be detected in the CSF, and its level increased over the ensuing week while the level of $\mathrm{OxyHb}$ gradually declined, imparting a yellow tinge to the CSF. The amount of bilirubin formed was felt to correlate with the number of erythrocytes hemolysed and the amount of $\mathrm{OxyHb}$ released, and bilirubin persisted in the CSF for up to 2 to 3 weeks after the 
hemorrhage. In this study MetHb was not detected in the CSF after SAH. In an in vitro experiment they found that whole blood left to incubate in CSF released OxyHb that converted to MetHb; bilirubin never appeared, suggesting that the action of living cells is necessary for its production. In a similar study of 62 patients after $\mathrm{SAH}$, Tourtellotte et al ${ }^{23}$ confirmed the rapid appearance of $\mathrm{OxyHb}$ in CSF, although they found that its increasing and then declining level over days became associated with an increasing proportion of MetHb as well as bilirubin. They found that the clearance of erythrocytes and pigments was highly variable, ranging from 6 to 30 days. Slow clearing was associated with old age, diabetes, vascular disease, and greater size and severity of SAH. Patients with slow clearing of their CSF had a more delayed (typically 11 days), and far higher, plateau in OxyHb levels. Corresponding to their more severe $\mathrm{SAH}$, these patients presented, and remained in poorer neurologic condition than "fast-clearers".

Mathews et al72 found that $20 \mathrm{ml}$ of whole human blood incubated in $10 \mathrm{ml}$ of normal CSF releases hemoglobin that fails to become bilirubin as it does when released in CSF in vivo, the factors necessary for the transformation apparently being absent in the blood clot and CSF alone.

Hemoglobin consists of two pairs of unlike polypeptide chains, each chain carrying an iron-containing heme moiety. The iron atom in $\mathrm{Hb}$ is in the ferrous form, which can bind oxygen reversibly and thus bestows $\mathrm{Hb}$ with its oxygen carrying capacity. Oxyhemoglobin, or oxygen bound $\mathrm{Hb}$, becomes $\mathrm{MetHb}$ through loss of electrons (oxidation) from the ferrous ion, converting it to the ferric state. This is a spontaneous reaction in the presence of water, and occurs extracellularly in the CSF or within subarachnoid clot. Either OxyHb or MetHb can be catabolized within certain cells into protein (globin), iron, and biliverdin (the remainder of the heme molecule). ${ }^{76}$ This cleavage is accomplished by a microsomal heme oxygenase system. Biliverdin is rapidly reduced by biliverdin reductase into bilirubin. In an experimental model of SAH in rats Roost et al 77 found that the enzymes necessary for bilirubin production after SAH in the central nervous system are found in arachnoid and choroid plexus. It is probable that macrophages migrating into the subarachnoid hematoma are also responsible for bilirubin formation in the CSF. ${ }^{78}$

Not all erythrocytes that escape entrapment in subarachnoid clot for freedom in the CSF undergo hemolysis. It has been shown that free erythrocytes in the subarachnoid space, which frequently reach levels of over one million cells per cubic $\mathrm{mm}$, travel with CSF flow to the arachnoid granulations where they engorge the villi. ${ }^{79}$ It remains unclear whether or not there exist in man any open channels through the villi into dural sinuses large enough to allow passage of whole erythrocytes. ${ }^{80}$ Ultrastructural examination of the arachnoid villi from several different animal species indicate that there is restricted passage of red cells into the circulation, many of the cells becoming entrapped in the central core of the villus to be digested by macrophages. 81,82 These findings are in agreement with tracer studies using labelled red blood cells injected into the subarachnoid space, which show most erythrocytes remain fixed in the arachnoid. ${ }^{83}$

In summary, clearance of erythrocytes from the CSF is accomplished by 3 basic mechanisms. The first is hemolysis, which begins immediately and reaches a plateau from 2 to 10 days after SAH, depending upon the size of the hemorrhage. It is hemolysis which liberates spasmogenic OxyHb in highest concentration around the subarachnoid arteries. Larger hemorrhages are associated with a more delayed (typically 7-11 days post-SAH) and much higher peak concentration in this pigment in the CSF, correlating with a higher risk of VSP. ${ }^{23}$ It is likely that there is an as of yet undefined $\mathrm{OxyHb}$ concentration and exposure time necessary for VSP to occur. The second mechanism is phagocytosis by macrophages, which occurs in the leptomeninges irritated by the hemorrhage, in the arachnoid granulations which become engorged with erythrocytes, and within the subarachnoid clot by migrating phagocytes. These macrophages, along with arachnoid lining cells and choroid plexus epithelium, appear to be the site of $\mathrm{Hb}$ metabolism to bilirubin, which is also released into the CSF and may play a role in the genesis of VSP. ${ }^{38}$ CSF xanthochromia resulting from hemolysis in the subarachnoid space is quite variable in duration, ranging from several to over 20 days. This time is dependent on a number of factors, but prominent among these is the volume of SAH. Direct passage of red blood cells across arachnoid villi into the venous circulation is of lesser significance in erythrocyte clearance from CSF. Normally, and in contrast to the situation with intravascular thrombi, the rate of spontaneous fibrinolysis in the CSF is too slow to substantially augment intact erythrocyte removal from the basal cisterns.

\section{Intrathecal Fibrinolytic Treatment after Aneurysmal SAH}

While intrathecal fibrinolysis after SAH is a new direction in managing patients with ruptured aneurysms, systemic antifibrinolytic therapy is not. Mullan et al ${ }^{84}$ observed that the plasminogen and t-PA inactivator epsilon aminocaprioc acid prolonged the duration of intraluminal clots in femoral arteries of dogs and reasoned that through the same mechanisms this agent might prevent dissolution of a thrombus sealing the rent in an aneurysm. Indeed, antifibrinolytic therapy has subsequently been shown to reduce the rate of rehemorrhage after aneurysm rupture, but the beneficial effect on outcome is negated by a concomitant increase in the incidence of VSP and delayed cerebral ischemia. 85,86 One explanation for this is that inhibition of already limited CSF fibrinolytic activity further delays clearance of vasogenic, hemolysing erythrocytes from the basal cisterns. Because of this risk, and because of the more widespread adoption of early aneurysm clipping to prevent rebleeding, antifibrinolytic agents no longer have a major role in the management of aneurysmal $\mathrm{SAH}^{87}$

Provided the ruptured aneurysm has been secured surgically it would be desirable to empty the basal cistern of hemolysing erythrocytes in order to prevent clot-mediated VSP. Because of the technical difficulties and hazards of an aggressive surgical evacuation of diffuse subarachnoid clot, interest has grown in accomplishing this task enzymatically with a fibrinolytic agent. The literature on the use of thrombolytic (or fibrinolytic, the terms are interchangeable) agents for intravascular thromboembolic disease, including stroke is extensive. ${ }^{88-91}$ In addition, urokinase has been used to lyse intracerebral and intraventricular hematomas in various experimental models. ${ }^{92,93}$ The concept of intrathecal fibrinolytic treatment after $\mathrm{SAH}$ is to augment the normally limited fibrinolytic activity of CSF and promote rapid digestion of the fibrin structure of the subarachnoid thrombus. Disruption and dissolution of the hematoma, aided by the 


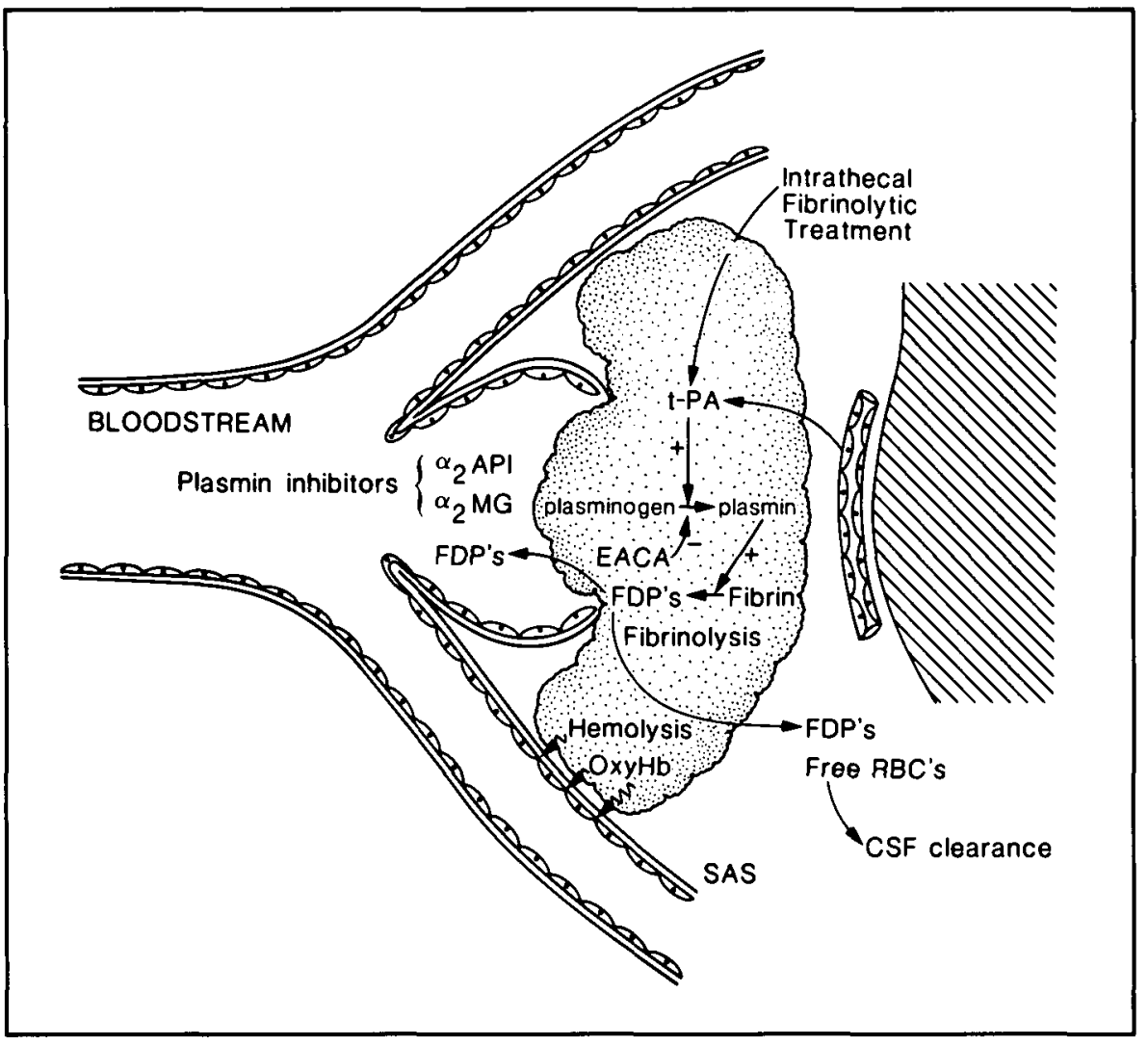

Figure 5 - Fibrinolysis in the subarachnoid space (SAS) is mediated by tissue plasminogen activator ( $t-P A)$ released mainly from endothelial cells of irritated blood vessels in the leptomeninges. T-PA binds to fibrin and converts plasminogen into plasmin, which in turn proceeds to split fibrin into various degradation products (FDPs). Plasmin inhibitors, including $\alpha$ 2-antiplasmin $(\alpha 2$ $A P I)$ and $\alpha 2$-macroglobulin ( $\alpha 2 M G$ ), are absent in the cerebrospinal fluid. Antifibrinolytic agents, such as epsilon aminocaproic acid (EACA), inhibit plasmin formation and hence retard fibrinolysis. The goal of intrathecal fibrinolytic treatment is to augment t-PA supplies to the subarachnoid clot and promote rapid fibrinolysis. which would allow clearance of red blood cells (RBSs) from the basal cisterns prior to their hemolysis, release of oxyhemoglobin $(\mathrm{Oxy} \mathrm{Hb})$, and vasogenic effect on the cerebral arterial wall. In order to prevent aneurysmal rebleeding, the aneurysm neck will have to be clipped prior to fibrinolytic treatment.

mechanical pulsatile force of the brain, could allow clearance of previously entrapped erythrocytes by bulk CSF circulation or $\mathrm{CSF}$ drainage prior to their hemolysis and release of $\mathrm{OxyHb}$ in high concentrations near the subarachnoid arteries (Figure 5).

Kennady appears to have been the first to instill a fibrinolytic agent into the subarachnoid space. ${ }^{94} \mathrm{He}$ found that the addition of "fibrinolysin" to an intrathecal irrigation system increased the efficiency of red blood cell removal from the CSF after experimental SAH in dogs. Peterson et al ${ }^{95}$ lysed an experimental subarachnoid clot in cats with a combination of streptokinase and streptodornase injected into the cisterna magna. They found that while this effectively cleared the hematoma it unfortunately produced a diffuse meningoencephalitis. Alksne et al injected plasmin into the cisterna magna of pigs one hour after the second injection of blood in a two hemorrhage model of experimental SAH and found that this reduced the severity of $\mathrm{SAH}$-induced histological changes in cerebral arteries compared to controls. ${ }^{96}$ In an extension of this work these same workers have reported that delaying plasmin injection 2,4 or 6 days after the second hemorrhage results in a progressive increase in the extent and severity of intimal proliferation, 97 a presumed marker of VSP. Cerebral angiography was not done in these studies. Some Japanese investigators have infused urokinase into the ventricles of patients after $\mathrm{SAH}$, with indeterminate results. 98

Our own work began with intrathecally administered rt-PA suspension into the basal cisterns of monkeys after experimental SAH. In a blinded, randomized, placebo-controlled trial it was found that $0.5 \mathrm{mg}$ of rt-PA (a dose chosen on the basis of in vitro studies) injected into the subarachnoid space 3 times over
24 hours beginning 24 hours after SAH uniformly lysed a mean clot volume of $4.38 \mathrm{ml}$ and virtually eliminated VSP measured at 7 days in the 12 treatment animals. ${ }^{12}$ In comparison, the 12 placebo animals all had a large volume of subarachnoid clot remaining and significant VSP in the clot-side cerebral vessels on day 7. Intrathecal rt-PA did not alter the coagulation profiles of the animals nor did it have any adverse effect on the microscopic appearance of the brain or meninges. A subsequent safety study using a much higher dose of intrathecal $\mathrm{rt}-\mathrm{PA}, 10 \mathrm{mg}$, also failed to show any adverse effect of the enzyme on neurologic condition of the animals, coagulation status or appearance of the brain on light microscopy. 13 Two animals in this study and 2 in the previous study developed temporary wound hemorrhages that were felt due to epidural leakage of the enzyme along the Ommaya catheter.

We then evaluated the efficacy of unilateral intraoperative administration of $\mathrm{rt}-\mathrm{PA}$ suspension $(0.5 \mathrm{mg})$ plus sustainedrelease gel rt-PA $(1.25 \mathrm{mg})$ in clearing a bilateral $6 \mathrm{ml}$ subarachnoid clot and preventing vasospasm in a randomized, placebocontrolled trial with 8 monkeys in each group. ${ }^{13}$ As in the original study, 1 placebo animal developed a delayed cerebral infarct. There were no incisional hemorrhages. In the placebo group significant VSP occurred in all major right and left-sided cerebral arteries and gross clot was found in the subarachnoid space in all animals. No significant vasospasm occurred in the treatment group and a single animal had a small fragment of clot left at 7 days. The development of the sustained-release gel rt-PA proved a significant advance because it obviated the need for an Ommaya reservoir and postoperative intrathecal injections. 
In the study reported here a dosage study was performed using gel rt-PA alone. It was found that 0.5 and $0.75 \mathrm{mg}$ of $\mathrm{rt}$ PA administered at the time of experimental SAH was effective in preventing VSP. Mild to moderate VSP was observed in all of the anterior cerebral vessels in the 0.125 and $0.25 \mathrm{mg}$ groups on day 7 . With an increasing dose of rt-PA there was a progressive decline in amount of clot remaining at 7 days. Two of the 4 animals from the $0.5 \mathrm{mg}$ group were free of clot, as were all of those in the $0.75 \mathrm{mg}$ group. It is noteworthy that the amount of VSP and clot remaining in the smallest dosage groups $(0.125$ and $0.25 \mathrm{mg}$ ) in this study was still significantly less than in the group of 12 nontreatment control animals reported previously (a mean 51,33 and $19 \%$ reduction in vessel caliber for the MCA, $\mathrm{C} 4$ and $\mathrm{C} 3$ respectively, and a mean remaining clot weight of $0.63 \mathrm{gm}$ after a $4.67 \mathrm{ml}$ volume $\mathrm{SAH}) .^{12}$ This suggests that even partial clot lysis is effective in reducing the severity of VSP in our model.

We remain optimistic that intrathecal thrombolysis with rtPA may prove to be effective preventative therapy for VSP after aneurysmal SAH. It will be necessary to employ it in conjunction with early aneurysm clipping, and to avoid the promotion of intracerebral hemorrhage it should probable not be used in patients with significant cortical disruption due to either the primary hemorrhage or surgery. In a recent Swedish study spanning 34 months, ${ }^{99}$ such early surgery was possible in $71 \%$ of 121 patients surviving transport to a neurosurgical center, and a similar percentage of these patients had thick localized or diffuse clot confined to the subarachnoid spaces. We are currently at work in our laboratory to determine the time interval after experimental SAH during which administration of rt-PA remains effective in significantly reducing the incidence of VSP.

\section{ACKNOWLEDGEMENTS}

This work was supported by grants from the Medical Research Council of Canada and by the National Institutes of Health (ROL N 525946-01) to Dr. Weir. Dr. Findlay is a fellow of the Alberta Heritage Foundation for Medical Research. The authors thank Arlene MacLean for preparing this manuscript.

\section{REFERENCES}

1. Epinosa F, Weir B, Shnitka T. Electron microscopy of simian cerebral arteries after subarachnoid hemorrhage and after the injection of horseradish peroxidase. Neurosurgery 1986; 19: 935945.

2. Hara $H$, Nosko M, Weir B. Cerebral perivascular nerves in subarachnoid hemorrhage. A histochemical and immunohistochemical study. J Neurosurg 1986; 65: 531-539.

3. Nosko M, Schulz R, Weir B, et al. Effect of vasospasm on levels of prostacyclin and thromboxane $A_{2}$ in cerebral arteries of the monkey. Neurosurgery 1988; 22: 45-50.

4. Epinosa F, Weir B, Shnitka T, et al. A randomized placebo-controlled double-blind trial of nimodipine after SAH in monkeys. Part 2: Pathological findings. J Neurosurg 1984; 60: 1176-1185.

5. Krueger C, Weir B, Nosko M, et al. Nimodipine and chronic vasospasm in monkeys: Part 2. Pharmacological studies of vessels in spasm. Neurosurgery 1985; 16: 137-140.

6. Espinosa F, Weir B, Overton T, et al. A randomized placebo-controlled double-blind trial of nimodipine after SAH in monkeys. Part 1: Clinical and radiological findings. J Neurosurg 1984; 60 : 1167-1175.

7. Nosko M, Weir B, Krueger C, et al. Nimodipine and chronic vasospasm in monkeys, Part 1 . Clinical and radiological findings. Neurosurgery 1985; 16: 129-136.
8. Nosko M, Weir BKA, Lundt A, et al. Effect of clot removal at 24 hours on chronic vasospasm after SAH in the primate model. J Neurosurg 1987; 66: 416-422.

9. Handa Y, Weir BKA, Nosko M, et al. The effect of timing of clot removal on chronic vasospasm in a primate model. J Neurosurg 1987; 67: 558-564.

10. Lewis PJ, Weir BKA, Nosko MG, et al. Intrathecal nimodipine therapy in a primate model of chronic cerebral vasospasm. Neurosurgery 1988; 22: 492-500.

11. Steinke DE, Weir BKA, Findlay JM, et al. A trial of the 21-aminosteroid $\mathrm{U} 74006 \mathrm{~F}$ in a primate model of chronic cerebral vasospasm. Neurosurgery (in press).

12. Findlay JM, Weir BK, Steinke D, et al. Effect of intrathecal thrombolytic therapy on subarachnoid clot and chronic vasospasm in a primate model of SAH. J Neurosurg 1988; 723-735.

13. Findlay JM, Weir BKA, Gordon P, et al. Safety and efficacy of intrathecal thrombolytic therapy in a primate model of cerebral vasospasm. Neurosurgery (in press).

14. Weir B, Grace M, Hanson J, et al. Time course of vasospasm in man. J Neurosurg 1978; 48: 173-178

15. Kwak R, Niizuma H, Ohi T, et al. Angiographic study of cerebral vasospasm following rupture of intracranial aneurysms. Part 1 : Timing of appearance. Surg Neurol 1979; 11: 257-262.

16. Fisher CM, Kistler JP, Davis JM. Relation of cerebral vasospasm to subarachnoid hemorrhage visualized by computed tomographic scanning. Neurosurgery $1980 ; 6: 1-9$.

17. Kistler JP, Crowell RM, Davis KR, et al. The relation of cerebral vasospasm to the extent and location of subarachnoid blood visualized by CT scan: A prospective study. Neurology (N.Y.) 1983; 33: 424-426.

18. Findlay JM, Weir BKA. Subarachnoid and intracerebral hemorrhage. In: Weinstein PR, Faden Al, eds. Protection of the Brain from Ischemia. Baltimore: Williams \& Wilkins 1989.

19. Bloomfield SM, Sonntag VKH. Delayed cerebral vasospasm after uncomplicated operation for an unruptured aneurysm. Case report. Neurosurgery 1985; 17: 792-796.

20. Kondziolka D, Bernstein M, Spiegel SM, et al. Symptomatic arterial luminal narrowing presenting months after subarachnoid hemorrhage and aneurysm clipping. J Neurosurg 1988; 69: 494-499.

21. White RP. Overview of the pharmacology of vasospasm. In Wilkins RH, ed. Cerebral Arterial Spasm. Baltimore: Williams \& Wilkins $1980 ; 229-236$.

22. Zervas NT, Liszczak TM, Mayberg MR, et al. Cerebral spinal fluid may nourish cerebral vessels through pathways in the adventitia that may be analogous to systemic vasa vasorum. J Neurosurg 1982; 56: 475-481.

23. Tourtellotte WW, Metz LN, Bryan ER, et al. Spontaneous subarachnoid hemorrhage: Factors affecting the cerebral spinal fluid. Neurology 1964; 14: 301-306.

24. Weir B. Aneurysm affecting the nervous system. Baltimore: Williams \& Wilkins 1987 ; 246-250.

25. Osaka K. Prolonged vasospasm produced by the breakdown products of erythrocytes. J Neurosurg 1977; 47: 403-411.

26. Toda N, Shimizu K, Ohta T. Mechanism of cerebral arterial contraction induced by blood constituents. J Neurosurg 1980; 53: 312-322.

27. Lellum GR, Irvine TW Jr, Zervas NT. Cerebral vasoactivity of heme proteins in vitro. J Neurosurg 1982; 56: 777-783.

28. Duff TA, Louie J, Feilbach JA, et al. Erythrocytes are essential for development of cerebral vasculopathy resulting from subarachnoid hemorrhage in cats. Stroke 1988; 19: 68-72.

29. Mayberg M, Akada T, Bark D. Cerebral arteriopathy and contractile changes after SAH are related to erythrocyte component of whole blood. Stroke 1988; 19: 130 (Abstr.).

30. Boullin DJ, Tagari P, Du Boulay G, et al. The role of hemoglobin in the etiology of cerebral vasospasm. An in vivo study of baboons. J Neurosurg 1983; 59: 231-236.

31. Ohta T, Kajikawa $H$, Yoshikawa $Y$, et al. Cerebral vasospasm and hemoglobins: clinical and experimental studies. $I n$ : Wilkins RH, ed. Cerebral Arterial Spasm. Baltimore: Williams \& Wilkins $1980 ; 166-172$. 
32. Fujii S, Fujitsu K. Experimental vasospasm in cultured arterial smooth-muscle cells. Part 1: Contractile and ultrastructural changes caused by oxyhemoglobin. J Neurosurg 1988; 69: 9297.

33. Asano T, Tanishima T, Sasaki T, et al. Possible participation of free radical reactions initiated by clot lysis in the pathogenesis of vasospasm after subarachnoid hemorrhage. In: Wilkins RH, ed. Cerebral Arterial Spasm. Baltimore: Williams \& Wilkins 1980; 190-201.

34. Okamoto S, Handa H, Handa Y. Hemolysate-induced release of prostaglandinlike substances from the canine cerebral arteries. Surg Neurol 1985; 23: 421-424.

35. Seifert V, Stolke D, Kunz U, et al. Influence of blood volume on cerebrospinal fluid levels of arachidonic acid metabolites after subarachnoid hemorrhage: experimental study on the pathogenesis of cerebral vasospasm. Neurosurgery 1988; 23: 313-321.

36. Paoletti $P$, Gaetani $P$, Grignani $G$, et al. CSF leukotriene $C_{4}$ following subarachnoid hemorrhage. J Neurosurg 1988; 69: 488-493.

37. Kanamaru K, Waga S, Kojima T, et al. Endothelium-dependent relaxation of canine basilar arteries. Part 2: Inhibition by hemoglobin and cerebrospinal fluid from patients with aneurysmal subarachnoid hemorrhage. Stroke 1987; 18: 938-943.

38. Duff TA, Feilbach JA, Yusuf $Q$, et al. Bilirubin and the induction of intracranial arterial spasm. J Neurosurg 1988; 69: 593-598.

39. Taneda M. Effect of early operation for ruptured aneurysms on prevention of delayed ischemic symptoms. J Neurosurg 1982; 57: 622-628.

40. Hindersin P, Endler S. Alterations of coagulation and fibrinolysis in cerebrospinal fluid in subarachnoid hemorrhage. J Neurosurg Sci 1986; 30: 183-186.

41. Barabas A. The effect of CSF on blood clotting. Min Neurochir 1970; 14: 314-323.

42. Hindersin P, Heidrich R, Endler S. Hemostasis in cerebrospinal fluid. Basic concept of antifibrinolytic therapy of subarachnoid hemorrhage. Acta Neurochir Suppl 34, 1984.

43. Kasuya H, Shimizu T, Okada T, et al. Activation of the coagulation system in the subarachnoid space after subarachnoid hemorrhage: serial measurement of fibrinopeptide $A$ and bradykinin of cerebrospinal fluid and plasma in patients after subarachnoid hemorrhage. Acta Neurochir (Wien) 1988; 91: 120-125.

44. Mullertz S. Fibrinolysis: an overview. Semin Thromb Hemostasis 1984; 10: 1-5.

45. Pennica D, Holmes WE, Kohr WJ, et al. Cloning and expression of human tissue-type plasminogen activator cDNA in E-Coli. Nature 1983; 301: 214-221.

46. Castellino FJ. Biochemistry of human plasminogen. Semin Thromb Hemostasis 1984; 10: 18-23.

47. Verstraete M, Collen D. Thrombolytic therapy in the 80 's. Blood 1986; 67: 1529-1541.

48. Alkjaersig N, Fletcher AP, Sherry S. The mechanism of clot dissolution by plasmin. J Clin Invest 1959; 38: 1086-1095.

49. Verstraete $M$. New thrombolytic drugs in acute myocardial infarction: theoretical and practical considerations. Circulation 1987; 76, Suppl II: 31-38.

50. Aoki, N, Harpel PC. Inhibitors of the fibrinolytic enzyme system. Semin Thromb Hemostasis 1984; 10: 24-41.

51. Bachmann F, Kruithof IEKO. Tissue plasminogen activator: chemical and physiological aspects. Semin Thromb Hemostasis 1984; 10: $6-17$.

52. Kwaan HC. The role of fibrinolysis in disease processes. Semin Thromb Hemostasis 1984; 10: 71-79.

53. Van Hinsberg VWM, Bertina RM, van Wijgaarden A, et al. Activated protein $\mathrm{C}$ decreases plasminogen activator-inhibitory activity in endothelial cell-condition medium. Blood 1985; 65: 444-451.

54. Collen D. On the regulation and control of fibrinolysis: Edward Kowalski memorial lecture. Throm Haemost 1980; 43: 77-89.

55. Porter JM, Acinapura AJ, Capp JP, et al. Fibrinolysis in the central nervous system. Neurology 1969; 19: 47-52.

56. Porter JM, Acinapura AJ, Capp JP, et al. Fibrinolytic activity in the spinal fluid and meninges. Surg Forum 1966; 17: 425-427.

57. Takashima S, Koga M, Tanaka K. Fibrinolytic activity of human brain and cerebrospinal fluid. Br J Exp Path 1969; 50: 533-539.
58. Astrup T, Mullertz S. The fibrin plate method for estimating fibrinolytic activity. Arch Biochem Biophys 1952; 40: 346-351.

59. Todd AS. Localization of fibrinolytic activity in tissues. Brit Med Bull 1964; 20: 210-219.

60. Kun-Yu Wu K, Jacobsen CD, Hoak JC. Plasminogen in normal and abnormal human cerebrospinal fluid. Arch Neurol 1973; 28: 6466.

61. Tovi D, Nilsson IM, Thulin CA. Fibrinolytic activity of the cerebrospinal fluid after subarachnoid hemorrhage. Acta Neurol Scandinav 1973; 49: 1-9.

62. Hassler O, Fodstad H. Fibrinolytic activity in the walls of cerebra saccular aneurysms. Acta Neurochir 1977; 37: 49-55.

63. Maurice-Williams RS, Gordon YB, Sykes A. Monitoring fibrinolytic activity in the cerebrospinal fluid after aneurysmal subarachnoid hemorrhage: a guide to the risk of rebleeding. J Neurol Neurosurg Psychiatry 1980; 43: 175-181.

64. Anderson M, Matthews KB, Stuart J. Coagulation and fibrinolytic activity of the cerebrospinal fluid. J Clin Pathol 1978; 31 : 488492.

65. Steinmetz $\mathrm{H}$, Grote E. The fibrinolytic activity of cerebrospinal fluid after subarachnoid hemorrhage. Neurol Res 1983; 5: 5965.

66. Vermeulen M, van Vliet HHDM, Lindsay KW, et al. Source of fibrin/fibrinogen degradation products in the CSF after subarachnoid hemorrhage. J Neurosurg 1985; 63: 573-577.

67. Fodstad H, Kok P, Algers G. Fibrinolytic activity of cerebral tissue after experimental subarachnoid hemorrhage: inhibitory effect of tranexamic acid (AMCA). Acta Neurol Scandinav 1981; 64: 29 64.

68. Fodstad H, Nilsson IM. Coagulation and fibrinolysis in blood and cerebrospinal fluid after aneurysmal subarachnoid hemorrhage: effect of tranexamic acid (AMCA). Acta Neurochir (Wien) 1981; 56: 25-38.

69. Okada Y, Tsuchiya T, Tada T, et al. Experimental study on plasminogen activator and trypsin inhibitor system in the cerebrospinal fluid and brain in cases of trauma and shock. Brain Nerve 1966; 18: 784

70. Guggiari M, Dagreou F, Rivierez M, et al. Prediction of cerebral vasospasm. Value of Fibrinogen Degradation Products (FDP) in the cerebro-spinal fluid (CSF) for prediction of vasospasm following subarachnoid hemorrhage due to a ruptured aneurysm. Acta Neurochir 1984; 73: 25-33.

71. Alpers BJ, Forster FM. The reparative processes in subarachnoid hemorrhage. J Neurol Pathol Exp Neurol 1945; 4: 262-268.

72. Matthews WF, Frommeyer WB Jr. The in vitro behavior of erythrocytes in human cerebrospinal fluid. J Lab Clin Med 1955; 45 : 508-515.

73. Froin G. Les hemorragies sous-arachnoidiennes et le mecanisme de l'hematolyse en general, Paris, G. Steinheil 1904.

74. Hammes EM Jr. Reaction of the meninges to blood. Arch Neurol Psychiatry 1944; 52: 505-514.

75. Barrows LJ, Hunter FT, Banker BQ. The nature and clinical significance of pigments in the cerebrospinal fluid. Brain 1955; 78 : 59-80.

76. Bauer JD. Hemoglobin, porphyrin, and iron metabolism. In: Kaplan LA, Pesce AJ, eds. Clinical Chemistry Theory Analysis and Correlation. St. Louis: C.V. Mosby Co 1984; 613-651.

77. Roost K, Pimstone NR, Diamond I, et al. The formation of cerebrospinal fluid xanthochromia afer subarachnoid hemorrhage. Enzymatic conversion of hemoglobin to bilirubin by the arachnoid and choroid plexus. Neurology 1972; 22: 973-977.

78. Pimstone NR, Tenhunen R, Seitz P, et al. The enzymatic degradation of hemoglobin to biopigments by macrophages. J Exp Med 1971; 133: 1264-1268.

79. Ellington E, Margolis G. Block of arachnoid villus by subarachnoid hemorrhage. J Neurosurg 1969; 30: 651-657.

80. Kida S, Yamashima T, Kubota T, et al. A light and electron microscopic and immunohistochemical study of human arachnoid villi. J Neurosurg 1988; 69: 429-435.

81. Alksne JF, Lovings ET. The role of the arachnoid villus in the removal of red cells from the subarachnoid space. An electron microscopic study in the dog. J Neurosurg 1972; 36: 192-200.

82. Gomez DJ, Potts G, Deonarine V. Arachnoid granulations of the 
sheep. Structural and ultrastructural changes with varying pressure differences. Arch Neurol 1974; 30: 169-175.

83. Adams JE, Prawirohardjo S. Fate of red blood cells injected into cerebrospinal fluid pathways. Neurology 1959; 9: 561-564.

84. Mullen S, Beckman F, Vailati G, et al. An experimental approach to the problem of cerebral aneurysm. J Neurosurg 1964; 21 : 838-845.

85. Vermeulen $M$, Lindsay KW, Murray GD, et al. Antifibrinolytic treatment in subarachnoid hemorrhage. N Engl J Med 1984; 311: $431-437$.

86. Kassell NF, Torner JC, Adams HP Jr. Antifibrinolytic therapy in the acute period following aneurysmal subarachnoid hemorrhage. Preliminary observations from the cooperative aneurysm study. J Neurosurg 1984; 61: 225-230.

87. Weir B. Antifibrinolytics in subarachnoid hemorrhage. Do they have a role? No. Arch Neurol 1987; 44: 116-118.

88. Marder VJ, Sherry S. Thrombolytic therapy: current status. First of two parts. N Eng J Med 1988; 318: 1512-1520.

89. Marder VJ, Sherry S. Thrombolytic therapy: current status. Second of two parts. N Eng J Med 1988; 318: 1585-1595.

90. Sloan MA. Thrombolysis and stroke. Past and future. Arch Neurol 1987; 44: 748-768.

91. del Zoppo GJ. Thrombolytic therapy and cerebrovascular disease. Stroke 1988; 19: 1174-1179.

92. Narayan RK, Narayan TM, Katz DA, et al. Lysis of intracranial hematomas with urokinase in a rabbit model. J Neurosurg 1985; 62: $580-586$.
93. Pang D, Sclabassi RJ, Horton JA. Lysis of intraventricular blood clot with urokinase in a canine model: Part 3. Effects of intraventricular urokinase on clot lysis and post hemorrhagic hydrocephalus. Neurosurgery 1986; 19: 553-572.

94. Kennady JC. Investigations of the early fate and removal or subarachnoid blood. Pacif Med Surg 1967; 75: 163-168.

95. Peterson EW, Choo SH, Lewis AJ, et al. Lysis of blood clot and experimental treatment of subarachnoid hemorrhage. In: Wilkins RH, ed. Cerebral Arterial Spasm. Baltimore: Williams \& Wilkins 1980; 625-627.

96. Alksne JF, Branson PJ, Bailey N. Modification of experimental post-subarachnoid hemorrhage vasculopathy with intracisternal plasmin. Neurosurgery 1986; 19: 20-25.

97. Alksne JF, Branson PJ, Bailey N. Modification of experimental post-subarachnoid hemorrhage vasculopathy with intracisternal plasmin. Neurosurgery 1988; 23: 335-337.

98. Shiobara R, Kawase T, Ebato K, et al. "Scavengery surgery" for subarachnoid hemorrage (II) continuous ventriculo-cisternal perfusion using artificial cerebrospinal fluid with urokinase. In: Auer L, ed. Timing of Aneurysm Surgery. Berlin: de Gruyter 1985; 365-372.

99. Hillman J, Von Essen C, Leszniewski W, et al. Significance of "ultra-early" rebleeding in subarachnoid hemorrhage. J Neurosurg 1988; 68: 901-907. 